УДК 664.87:[634.739.1/.3]

\title{
ТЕПЛОФИЗИЧЕСКИЕ ХАРАКТЕРИСТИКИ ВОДНЫХ И ВОДНО-СПИРТОВЫХ ЭКСТРАКТОВ ЯГОД КЛЮКВЫ И ГОЛУБИКИ
}

\author{
() В.В. Сорокопуд, И.Б. Плотников", Л.В. Плотникова \\ Кемеровский технологический институт пищевой промышленности, \\ бульвар Строителей, 47, Кемерово (Россия), e-mail: plotnikov-ib@mail.ru
}

Исследованы теплофизические свойства водных и водно-спиртовых экстрактов ягод клюквы и голубики. Получены регрессионные уравнения, описывающие теплофизические свойства экстрактов, которые могут быть использованы в инженерной практике. Полученные данные о теплоемкости и теплопроводности экстрактов ягод клюквы и голубики пополняют информационную базу о свойствах ягодных экстрактов.

Ключевые слова: экстракты, клюква, голубика, удельная теплоемкость, коэффициент теплопроводности.

\section{Введение}

Пищевые продукты, обогащенные экстрактами из растительного сырья, входят в обширную группу продуктов питания функционального назначения, способствующих сохранению и улучшению здоровья населения [1].

Применение экстрактов в качестве добавок не ограничивается только обогащением продуктов биологически активными компонентами, они применяются в качестве [2] ароматизаторов, корректоров вкуса, стабилизаторов качества при хранении; БАДов, корректоров органолептических характеристик и т.п.

Для Сибирского региона перспективным сырьем при производстве натуральных экстрактов являются дикорастущие ягоды. Ценность дикорастущих ягодных растений состоит в том, что они имеют относительно высокую приспособленность к местным условиям и проявляют иммунитет ко многим заболеваниям. В связи с этим дикорастущие растения имеют наиболее стабильные урожаи по сравнению с культурными.

\section{Экспериментальная часть}

Объект исследования. Особое место среди дикорастущих ягод Сибирского региона занимают ягоды клюквы и голубики благодаря их химическому составу [3, 4].

Несмотря на все положительные стороны качеств данных ягод, их переработка не является массовым производством. Отчасти это связанно с отсутствием гибкой, легко перенастраиваемой схемы переработки данного вида сырья и ее аппаратурного оформления.

Разработка новых линий по производству экстрактов из ягодного сырья повлечет за собой разработку нового оборудования и усовершенствования уже существующего. Для этого в свою очередь потребуется широкая информационная база по свойствам экстрактов. Так, для подбора и расчета теплообменных и выпарных установок важными параметрами являются теплоемкость и коэффициент теплопроводности экстрактов. Несмотря на то, что работа по пополнению информационной базы по теплофизическим свойствам

Сорокопуд Валентина Васильевна - доцент, кандидат технических наук, e-mail: Lybanya_09@mail.ru

Плотников Игорь Борисович - старший преподаватель, кандидат технических наук, e-mail: plotnikov-ib@mail.ru

Плотникова Любовь Васильевна - аспирант, e-mail: Lybanya_09@mail.ru экстрактов ведется [5, 6], данных по теплофизическим свойствам экстрактов клюквы и голубики в доступной литературе не найдено. Данная работа посвящена экспериментальному исследованию теплофизических свойств экстрактов ягод клюквы и голубики.

\footnotetext{
* Автор, с которым следует вести переписку.
} 
Методы исследования. Экстракты являются термолабильными продуктами, что накладывает ограничения на область эксперимента, поэтому свойства экстрактов определяли в интервале температур 20$50{ }^{\circ} \mathrm{C}$. Содержание сухих растворимых веществ $\mathrm{C}_{\text {св }}$ изменяли в пределах 5-46 мас. \%, концентрацию спирта $\mathrm{C}_{\text {сп }}-$ 0-60 об. \%. Диапазоны варьирования параметров были приняты в результате теоретического и экспериментального исследования процессов экстрагирования ягод и концентрирования экстрактов в роторном распылительном испарителе [7]. Шаг варьирования параметров при определении свойств составлял: для температуры $-5^{\circ} \mathrm{C}$, для содержания сухих растворимых веществ - 9 мас. \%, для концентрации спирта - 10 об. \%.

Экстракты готовились методом настаивания на воде с последующим концентрированием (до содержания сухих веществ 63-65 мас. \%). Растворы (экстракты заданного состава) получали смешением рассчитанных объемов заранее полученных концентрированных водных экстрактов, дистиллированной воды и спирта (концентрацией 95 об.\%).

Исследования теплофизических свойств проводили с применением известных методик. Теплопроводность экстрактов определяли сравнительным методом Христианса [8]. Метод основан на сравнении образца исследуемого экстракта с эталоном, обладающим хорошо изученной и не подвергающейся изменениям теплопроводностью. В качестве эталонной жидкости использовали химически чистый глицерин, теплопроводность которого в исследуемом диапазоне изменяется в пределах $\pm 2 \%$. Удельную теплоемкость исследовали калориметрическим методом [8].

Измерения по определению теплофизических свойств повторяли не менее трех раз. Конечное значение параметра брали, как среднее арифметическое значение результатов, прошедших через барьер явно недостоверных.

Количество значений каждого параметра принятых при анализе и обобщений составляло 140 для экстрактов ягод клюквы и голубики соответственно.

\section{Результаты и их обсуждение}

Для анализа теплофизических характеристик экстрактов рассмотрим частные зависимости в виде поверхностей отклика, представленные на рисунках 1-4, полученные в результате статистического анализа.

Из анализа данных, представленных на рисунках 1, 2, видно, что при повышении температуры удельная теплоемкость экстрактов возрастает. С увеличением концентрации сухих веществ теплоемкость снижается, а с возрастанием содержание спирта увеличивается.

Как следует из данных, представленных на рисунках 3, 4, с ростом температуры теплопроводность экстрактов возрастает, причем эта зависимость линейная. С повышением концентрации сухих веществ, как и спирта, теплопроводность уменьшается.

Для установления функциональной зависимости между тремя независимыми переменными - $\mathrm{t}, \mathrm{C}_{\mathrm{cB}}$, $\mathrm{C}_{\text {сп }}$ и откликом - теплофизическими свойствами использовали множественный регрессионный анализ.

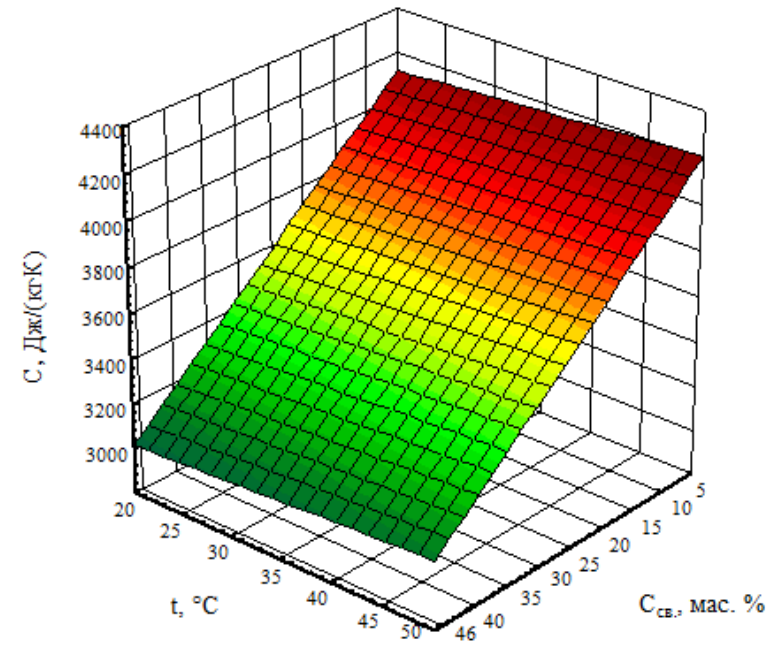

Рис. 1. Зависимость удельной теплоемкости экстрактов ягод клюквы от температуры и содержания сухих веществ

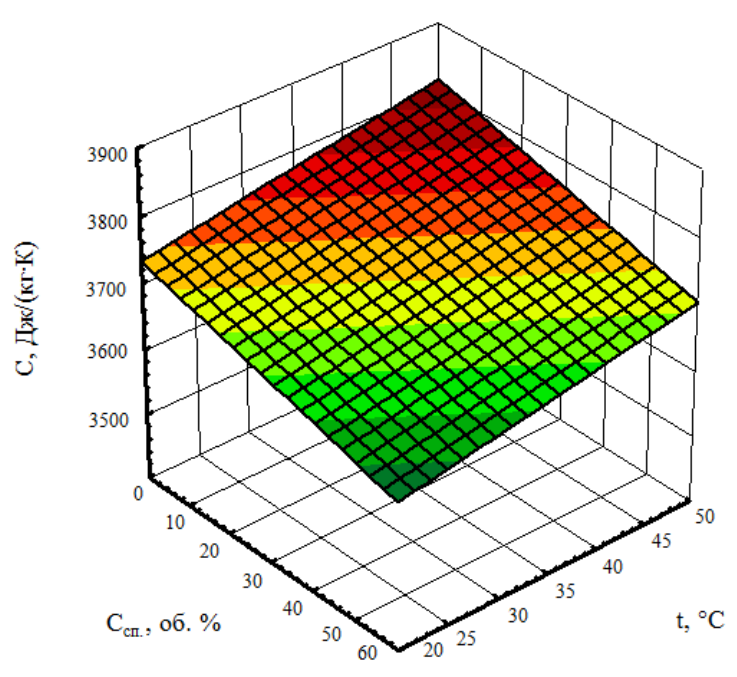

Рис. 2. Зависимость удельной теплоемкости экстрактов ягод голубики от температуры и содержания спирта 


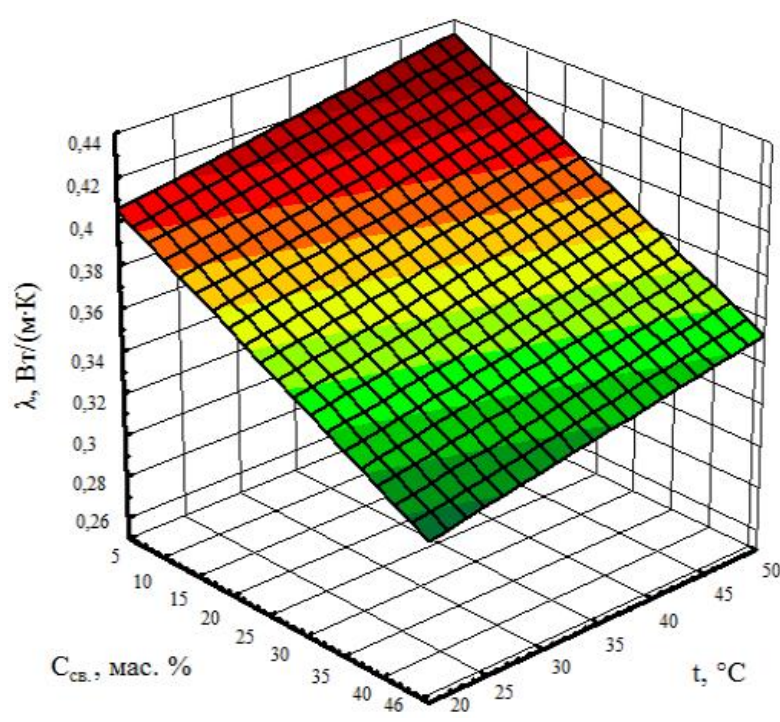

Рис. 3. Зависимость коэффициента теплопроводности экстрактов ягод клюквы от температуры и содержания сухих веществ

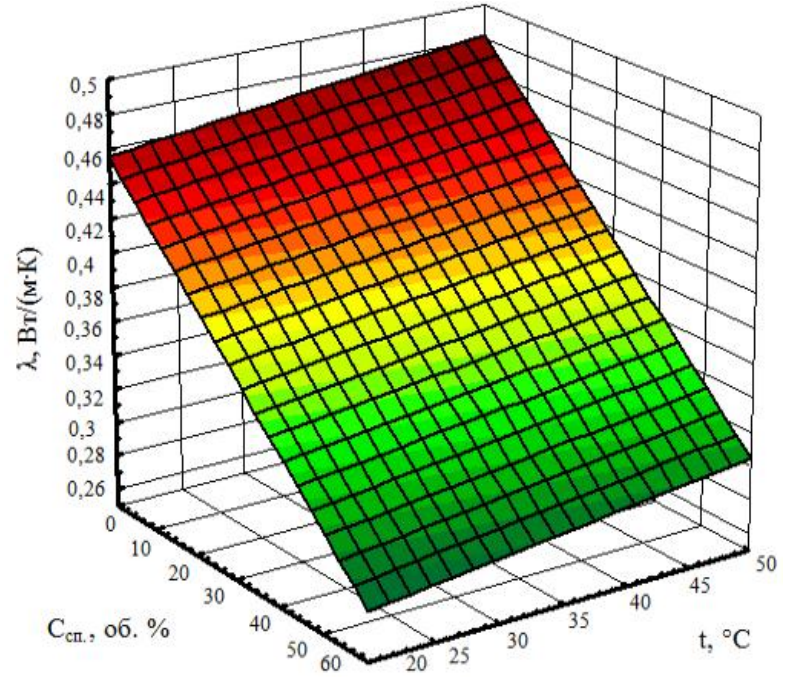

Рис. 4. Зависимость коэффициента теплопроводности экстрактов ягод голубики от температуры и содержания спирта

Полученные опытные данные были обработаны на ЭВМ в среде статистического пакета STATISTICA. В результате получены статистические модели, описывающие теплофизические свойства экстрактов.

Для удельной теплоемкости (Дж/(кг·К)) экстрактов клюквы и голубики уравнения множественной регрессии имеют вид

клюква

$$
\mathrm{C}_{\mathrm{K}}=4231,75-26,875 \cdot \mathrm{C}_{\mathrm{cв}}-1,621 \cdot \mathrm{C}_{\text {сп }}+3,112 \cdot t \quad \mathrm{R}=97,2 \%,
$$

голубика

$$
\mathrm{C}_{\Gamma}=4148,82-20,625 \cdot \mathrm{C}_{\mathrm{Cв}}-1,901 \cdot \mathrm{C}_{\mathrm{cп}}+2,812 \cdot t \quad \mathrm{R}=98,1 \%,
$$

где $\mathrm{R}$ - величина коэффициента множественной регрессии. Величина $\mathrm{R}$ показывает, что модель адаптирована и объясняет соответственно 97,2 и 98,1\% изменения удельной теплоемкости.

Для коэффициентов теплопроводности $(\mathrm{BT} /(\mathrm{M} \cdot \mathrm{K}))$ экстрактов клюквы и голубики уравнения имеют вид клюква

$$
\lambda_{\mathrm{K}}=\left(49,758-0,216 \cdot \mathrm{C}_{\mathrm{cв}}-0,359 \cdot \mathrm{C}_{\mathrm{сп}}+0,093 \cdot t\right) \cdot 10^{-2} \quad \mathrm{R}=96,8 \%,
$$

голубика

$$
\lambda_{\text {г }}=\left(47,983-0,186 \cdot \mathrm{C}_{\mathrm{cв}}-0,305 \cdot \mathrm{C}_{\mathrm{cп}}+0,095 \cdot t\right) \cdot 10^{-2} \quad \mathrm{R}=97,5 \%,
$$

Анализ уравнений $(1,2)$ показывает, что имеет место достаточно близкий характер влияния варьируемых параметров на теплоемкость исследуемых экстрактов. Аналогичное заключение можно сделать, сопоставляя уравнения $(3,4)$. На наш взгляд, это можно объяснить близким химическим составом и природой исследуемых ягодных экстрактов.

\section{Выводы}

Исследовано влияние температуры, содержания сухих веществ и концентрации спирта на теплоемкость и теплопроводность экстрактов ягод клюквы и голубики.

Полученные регрессионные уравнения пополняют информационную базу о теплофизических свойствах ягодных экстрактов и могут быть использованы в инженерной практике. 


\section{Список литературы}

1. Кравченко С.Н., Павлов С.С. Производство обогащенных продуктов с использованием экстрактов и их товароведная оценка. М.; Кемерово, 2006. 151 с.

2. Сарафанова Л.А. Применение пищевых добавок: технические рекомендации. 5-е изд. СПб., 2002. 160 с.

3. Юрков А.С. Ягодные культуры в Кузбассе. Кемерово, 1979. 205 с.

4. Кожевников Ю. П. Семейство вересковые (Ericaceae) // Жизнь растений: в 6 т. Т. 5. Ч. 2. Цветковые растения / под ред. А.Л. Тахтаджяна. М., 1981. С. 88-95.

5. Сорокопуд А.Ф., Третьякова Н.Г., Мустафина А.С. Теплофизические характеристики экстрактов красной рябины и красной смородины // Пиво и напитки. 2000. №4. С. 58-59.

6. Сорокопуд А.Ф., Гриценко В.В. Теплофизические характеристики экстрактов боярышника кроваво-красного и калины обыкновенной // Пиво и напитки. 2008. №2. С. 46-47.

7. Сорокопуд А.Ф. Разработка и совершенствование роторных распылительных аппаратов с целью интенсификации процессов в гетерогенных газожидкостных системах: дис... доктора техн. наук. Кемерово, 1998. 529 с.

8. Гинзбург А.С., Громов М.А., Красовская Г.И. Теплофизические характеристики пищевых продуктов. М., 1980. $288 \mathrm{c}$.

Поступило в редакиию 1 ноября 2013 г.

После переработки 15 января 2014 г.

Sorokopud V.V., Plotnikov I.B. , Plotnikova L.V. THERMAL AND PHYSICAL CHARACTERISTICS OF AQUEOUS AND AQUEOUS-ALCOHOLIC EXTRACTS OF COWBERRY AND BLUEBERRY

Kemerovo Technological Institute of Food Industry, Stroitelei st., 47, Kemerovo (Russia), e-mail: plotnikov-ib@mail.ru

Wild berries are the common raw materials for natural extracts production in Siberia. Wild berries value consists in the greatest adaptation to the local conditions and virus security. Cowberries are rich in vitamin C. It is approximately the same as in oranges, grapefruits, lemons and strawberry. Blueberry has long been known to prevent Barlow disease, furthermore they enhance the gastric acid isolation and favor digestion. In spite of these berries advantages they are not massively processed. It depends on technological processes inadequacy and insufficient information of semi-processed and finished products.

Thermal and physical properties of aqueous and aqueous-alcoholic extracts of cowberry and blueberry are investigated. Regression equations defining the thermal and physical properties of extracts used in engineering practice are obtained. The heat capacity and thermal conductivity of cowberry and blueberry extracts data enlarge an information base of berry extracts properties.

Keywords: extracts, cowberry, blueberry, heat capacity, thermal conductivity index.

\section{References}

1. Kravchenko S.N., Pavlov S.S. Proizvodstvo obogashchennykh produktov s ispol'zovaniem ekstraktov $i$ ikh tovarovednaia otsenka. [Production of products using enriched extracts and Evaluation]. Moscow; Kemerovo, 2006, 151 p. (in Russ.).

2. Sarafanova L.A. Primenenie pishchevykh dobavok: Tekhnicheskie rekomendatsii. [The use of food additives: Technical Recommendations]. 5 ed. St. Petrsburg, 2002, 160 p. (in Russ.).

3. Iurkov A.S. Iagodnye kul'tury v Kuzbasse. [Berry crops in the Kuzbass]. Kemerovo, 1979, 205 p. (in Russ.).

4. Kozhevnikov Iu.P. Zhizn' rastenii. [Plant life]. vol. 5, part. 2. Tsvetkovye rasteniia. [Flowering plants]. Ed. A.L. Takhtadzhian. Moscow, 1981, pp. 88-95. (in Russ.).

5. Sorokopud A.F., Tret'iakova N.G., Mustafina A.S. Pivo i napitki, 2000, no. 4, pp. 58-59. (in Russ.).

6. Sorokopud A.F., Gritsenko V.V. Pivo i napitki, 2008, no. 2, pp. 46-47. (in Russ.).

7. Sorokopud A.F. Razrabotka $i$ sovershenstvovanie rotornykh raspylitel'nykh apparatov $s$ tsel'iu intensifikatsii protsessov $v$ geterogennykh gazozhidkostnykh sistemakh: dis... d-ra tekhn. nauk. [Development and improvement of rotary spray devices for the purpose of intensification of processes in heterogeneous gas-liquid systems: the thesis of Doctor of Technical Sciences]. Kemerovo, 1998, 529 p. (in Russ.).

8. Ginzburg A.S., Gromov M.A., Krasovskaia G.I. Teplofizicheskie kharakteristiki pishchevykh produktov. [Thermal characteristics of foods]. Moscow, 1980, 288 p. (in Russ.).

Received November 1, 2013

Revised January 15, 2014

\footnotetext{
"Corresponding author.
} 